\title{
REVISING TEACHING EXERCISES TO ENGAGE FIRST-YEAR UNDERGRADUATE SOCIOLOGY STUDENTS
}

\author{
Edgar Burns
}

\section{INTRODUCTION}

This article describes an extended re-evaluation and reflection on a teaching activity. The revision of a previously used first-year undergraduate sociology teaching exercise checked its relevance in a different national and institutional context. Continued relevance of the exercise was confirmed and the new iteration showed additional elements could be introduced into the exercise, enriching student learning. This ongoing teacher reflection also identified potential application to social research classes, creating further pedagogical value.

The present teacher reflection draws on the original 'bathroom politics' class exercise, often described by students as the "which-way-should-the-toilet-roll-hang?" class (Burns, 2003). This description presents the process of reusing this existing teaching exercise and making changes while doing so. The discussion demonstrates how instructors can adapt and extend a teaching exercise from its first formulation or use. Rather like the environmental mantra, "reuse, repurpose, recycle", such adaptive logics have relevance to teaching exercises, adding value to prior teaching development efforts in the same or different fields.

Using the original 'bathroom politics' exercise got students thinking about usually unnoticed bathroom rules that create toilet protocols and etiquette in western societies' domestic household settings. The exercise was devised to introduce beginning sociology students to small-class interactive learning - learning to speak up in the academic environment, and starting to understand threshold sociological concepts of norms and roles. The original article has been occasionally cited (Kaufman \& Schoepflin, 2009, pp. 24, 28; Nefes, 20I3) and used as a template for similar teaching exercises creating sociological insight using taboo or "unspoken about" social practices (Paul, 2006).

\section{BACKGROUND AND CONTEXT}

Active pedagogy benefits by revisiting teaching exercises. This original class exercise started with the following question written on the whiteboard: "Which way should toilet-paper hang?" After a few smiles and comments, and sometimes further explanation, students were asked one by one whether they thought toilet-paper should hang 'in' or 'out.' The sociological teaching purpose was to get students to see that there are many invisible rules that govern social behaviour, even in apparently unimportant aspects of daily living. At the beginning of first-year tertiary life, there is also an issue of breaking the ice socially and academically in the classroom so that students begin to express themselves in front of others at post-high school level. This exercise achieved this. Without much explicit coaxing, students were drawn into participating: first by committing temporarily to an opinion written on the whiteboard and then being innocently asked to explain why they hold the view they had just expressed. Discussion skirting round a mildly taboo area of personal and household behaviour created interest and a certain buzz amongst students as they began 'doing sociology.' 


\section{Rationale}

Student class exercises and case studies have a long history, whether done individually or as a group. They range from the famed Harvard case study approach (Forman \& Rymer, 1999) to scenarios created for graded assignments, through to use for "in the moment" discussion and analysis in classes and small groups (George \& Bennett, 2004). Exercises or case studies can involve the description of real or created examples, issues, relationships, clientprofessional situations, or similar circumstances. Turcsanyi-Szabo et al. (2006, p. 343) described adaptations in problem-based approaches to student learning, distinguishing between teaching and learning as follows:

We need to reconsider our teaching aims and methods and reflect on our own faults, trying to look for early remedies that might improve the situation. There are several examples in learning theory that suggest promises which need to be revisited.

Shulman (1998, p. 5) proposed that such scholarship or reflection should be public, susceptible to critical review and evaluation, and accessible for exchange and use by other members of one's scholarly community. This applies equally to teaching exercises as to any other instructional or curriculum element (Biggs \& Tang, 2007). It includes both deepening learning (Burns 2016, 2017) and learning from mistakes (Metzger, 2003), and ideally involves the personal learning of the instructor in the act of engaging students in their learning (Trigwell \& Shale, 2004).

Many disciplines' journals present teaching exercises and related pedagogical practices for engaging students and communicating effectively (Nye et al., 20II). Experimenting with Brouillette and Turner's (1992) classic sociology exercise is described in the next section. Such published accounts can potentially be adapted by others to their own teaching circumstances. Many instructors do so, enhancing their teaching but without necessarily reporting in the literature how they have modified or extended these teaching tools.

Valuable examples of scholars actively re-examining and re-working teaching exercises include Sullivan's (20II) adaptation of a traditional engineering teaching exercise "The egg-drop exercise revisited" from Warner (2005) for teaching entrepreneurship; Bryant's (1994) description of revisiting a biology teaching exercise; or Rosenquist's (2012) re-analysis of class engagement of students for revising letters. Chappell (2007, p. 259) commented "Unless lecturers engage in critical reflection and on-going discovery they stay trapped in unexamined judgements, interpretations, assumptions and expectations." Boyd and Boyd (2005) described instructors using a personal diary to assist such reflection.

\section{Example: Changing Teaching Settings for Existing Exercises}

Applying this kind of teaching renovation practice in relocating to a new institution provided an opportunity to experiment with Brouillette and Turner's (1992) famous sociology teaching exercise. This involved getting students to spit into a spoon in order to - somewhat theatrically - make a point about how we define normal and deviant.

In emulating Brouillette and Turner's exercise for the first time, the 'yuck' factor of student revulsion at the saliva-in-the-spoon sample was evoked as expected. Thus, in similar fashion to the original exercise, it provided the platform for strongly engaging students' attention to make the teaching point. The sociological intention was to show students there was no chemical, biological or other difference between 'spit' and 'saliva,' only the social definitions students made, such as believing saliva exchange between kissing couples acceptable and natural, but similar intimate contact when saliva was defined as 'spit' unacceptable and even 'horrible.' The original article, brief though it was, explained the teaching exercise beautifully.

A key difference was seen, however, using Brouillette and Turner's exercise two decades after it was first published. One or two students showed willingness to contemplate swallowing the spoon of spit if enough urging or pressure 
seemed likely to emerge from the social interaction of instructor and class-mates. This seemed to show a realityTV show mentality about doing things as a dare even if defined as revolting or deviant. In such shows contestants are seen standing in mud, coping with flies or other insects, or eating worms. Some students appeared to be applying this modus operandi in the contemporary classroom (Montemurro, 2008). One student advised friends who were being solicited for a saliva sample, "Don't do it. It's a trick!" which was quite disruptive to the exercise though raising student engagement - and again seemed to stem from a reality-TV idea about 'making yourself'do something 'yucky,' or in a minor way socially deviant.

Such reactions illustrate how any given teaching exercise, over time, is gradually positioned differently. Reality TV with its 'dare' mode of participation was uncommon when the saliva exercise was published. How students respond, and the usefulness of teaching exercises, needs periodic review.

\section{PROCESS}

\section{Observation I: Does the Exercise Still Resonate with Students?}

Figure I presents reconstructed data from one class comprising 24 students. Actual results from each class varied, some having more 'ins' than 'outs' or vice versa, expressing opinions which way toilet-paper should hang. Like former iterations using this class exercise, having got students temporarily committed to an 'in' or 'out' opinion, visually drawn on the whiteboard like Figure I, the second part of the exercise was to go round students asking them, "Why did you choose the answer that you did?" With a bit of prompting and drawing out the quieter ones, and sometimes a student's comment/question on another student's response, everyone found they had something to say from their own experience. The discovery of patterns of behaviour and normative expectations which differ - sometimes markedly - from their own, in other people's private worlds, for many in this new cohort of students was revelatory.

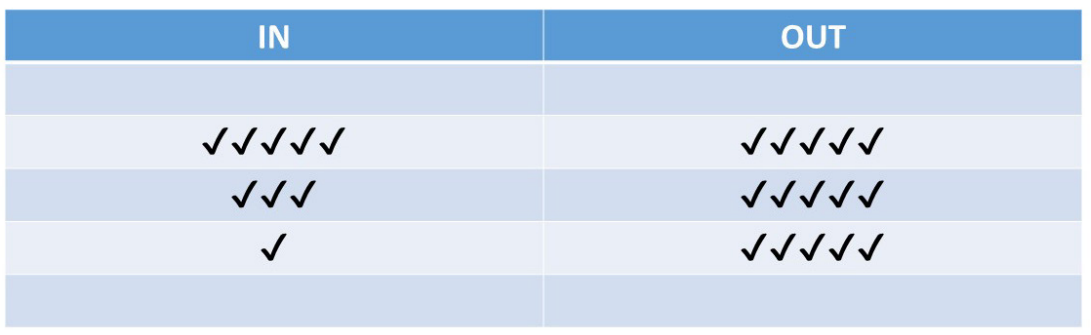

Figure I. Standard data collection table.

After a gap of four years from having used this exercise to teach first-year sociology to an older mix of 'nontraditional' students (Law, 2007) in New Zealand, questions about using this exercise once again included whether it would work in a new institutional environment, and in groups with a greater proportion of late-teen students in each class. The first observation, then, was that the exercise evoked a similar buzz to previous classes, and its currency had not waned. These new university students gained a small window into private bathroom rules and norms of their fellow classmates. Seeing the contrasting answers on the whiteboard, and listening to justifications for opposing views over a mildly taboo subject, again evoked interest and attention to how social rules and norms are created and maintained. 


\section{Observation 2: Extending the Exercise Quantitatively}

A variation introduced almost incidentally in the current classroom version of this exercise was a new step (Figure 2). Students were invited to spend a few moments as a group considering the implications of this newly collected evidence before them on the whiteboard. Then, following the previously second step, students were encouraged to discuss why they had made their 'in' or 'out' choices, drawing on their own experiences and beliefs about bathroom behaviour and rules.

\begin{tabular}{|c|cc|}
\hline IN & OUT & \\
\hline$\checkmark \checkmark \checkmark \checkmark \checkmark$ & $\checkmark \checkmark \checkmark \checkmark \checkmark$ & \\
\hline$\checkmark \checkmark \checkmark \checkmark$ & & \\
\hline$\checkmark$ & & \\
& & \\
\hline 10 & 15 & 25 \\
\hline $40.0 \%$ & $60.0 \%$ & $100.0 \%$ \\
\hline & & \\
\hline
\end{tabular}

Figure 2. Raw data plus basic statistics..

But a new step involved drawing lines on the whiteboard at the bottom of the table, below the data. Students were asked to sum each column downwards, calculate totals, and then add the totals horizontally to the right hand side. Immediately these numbers made it possible to compose a sentence: "Ten out of twenty-five of the class prefer the toilet roll hung inwards, and fifteen out of twenty-five prefer rolls hung out" - or whatever it was for a given class. Reading a data table, and expressing the numbers in words, is an important practical skill.

This simple maths can be further extended, converting the raw totals into percentages. In teaching first-year classes, numeracy skills vary from some who would be comfortable doing science, to a sizable proportion of students who had chosen social subjects, consciously avoiding anything numerical.

Bearing that demographic in mind, briefly tallying the numbers/percentages allowed the instructor to step through this most basic of statistics, showing how the percentages are calculated for those needing this piece of learning. From Figure 2, this could be stated in words, either by the instructor or soliciting students to make the effort: "Forty per cent of responses prefer toilet-paper hung in the 'in' position, while a majority of sixty per cent prefer toilet rolls hung in the 'out' position." Today, phone apps can be used to help students do this.

It was possible to lead the discussion more widely by asking students, "What, overall, does the evidence on the whiteboard tell us? What generalisations can we make?" Students made comments like, "More people prefer rolls hung 'in' or 'out'," depending on the class result. If they sensed the importance of the quantitative aspect of things here, students often tried to use the percentages in their replies. Pushing them further, I asked, "Could we say, for instance, that forty per cent of the whole country prefers 'in' and sixty per cent prefers 'out'?"

Depending on their answers, I reminded them about different responses in other classes, and we explored questions of sampling (their class being just one sample), generalisation and over-generalisation. The idea of extrapolation from class to whole populations can be inserted into the conversation - what are the issues involved? Together we could identify that it is the class members from whom the data comes; as a group of mostly younger tertiary students, why might their percentage not apply nationally? 


\section{Observation 3: Introducing a Qualitative Intensity Measure}

An innovation that departed sharply from the original exercise introduced a much clearer view of the strength of student opinions on this topic. This was the introduction of a five-point Likert question on the whiteboard after initially collecting and discussing 'in' and 'out' responses. The five-response categories offered a hierarchy of choice for students rating how strongly - or not - they held their views when answering the original question about which way toilet-paper should hang. Figure 3 reconstructs results achieved using a Likert question to measure the degree of intensity students felt committing to their original 'in' or 'out' opinion. This time responding to, "How strongly do you hold the opinion you expressed earlier? Place yourself in one of the five categories listed on the whiteboard, between high at rating five to low at rating one."

What did this new data do for the discussion? Firstly, there was an additional buzz around groups as the extra layer of revelation became apparent as students in turn gave their answers. Again, the teaching purpose of involving everyone was reinforced, that participation was not hard, and students could learn something about other peoples' feelings with little self-disclosure. More specifically, for three of the males in one class, this was an appropriate release-valve that permitted them to honestly declare that they did not care for this measure, but had simply chosen a number to be obliging since everyone was choosing a number.

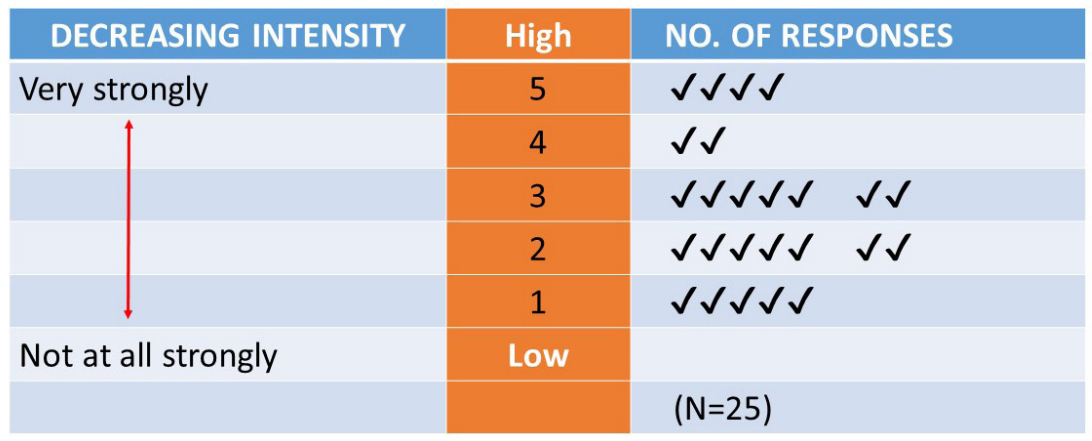

Figure 3. Raw data of intensity measure.

\section{DISCUSSION}

As a result of revisiting this toilet-paper exercise, the two modifications of $(I)$ the introduction of a basic quantitative aspect, and (2) the development of an intensity measure led to discussing this exercise in second-year undergraduate research methods classes (Haney, 2009). Here, it was not the buzz of novelty that engaged beginning sociology students' interest but an opportunity to learn about research methodology: that is, talking about the toilet-paper exercise in class with students who know they are then going to write a report about research issues in datacollecting illustrated in the exercise. Some students had already experienced the first-year exercise.

Using the safety and convenience of the topic, students were able to traverse strengths, weaknesses, issues and limitations common in one form or another in any research project. They were able to compare qualitative and quantitative aspects. They used the discussion of the class exercise to understand better how similar it was to a focus-group. The intensity data as a second round of focus-group process provided a concrete example to discuss Likert scales and go beyond yes/no responses to strength of attitudes and views. Over a number of research classes, it became apparent that many of the issues on serious social research were embedded in the light-hearted toilet-paper exercise. What were the exercise's methodological strengths and weaknesses? Research students were invited to reflect on teacher ethics and research ethics - where were there overlaps and what should be separated out? 


\section{Socially Acceptable Responses/Response Bias}

The original data collecting phase (Figure I) had an artefact in the data collection method used in the classroom that was subordinated to the teaching purposes of ice-breaking and getting students 'doing sociology' in first-year classes. That is, the pedagogical purpose bracketed out important underlying research questions. For learning purposes with the more advanced students, however, we explored such issues further.

It is noticeable in conducting first-year exercise that when the instructor goes round the class getting each student in turn to commit to an answer, either 'in' or 'out', there can be a run of three or four students in succession choosing one option rather than the other. At times this has been, in the banter of class interaction, an opportunity to tease students: "Are we going to maintain this streak of a given choice, or will we get an independent thinker breaking for the other option of 'in' or 'out'?"

Putting the fun aspect of classroom management aside, this raised a problem as a data collection method in conducting objective investigations. The question for students was, "What is the flaw here?" The problem was the influence that one student, or a run of students choosing one option, may have on the next selection. Choice/ selection independence is problematic. Students, especially those new to tertiary study, are often very sensitive to what their peers are doing or saying, and the need for joke with them about how they are deciding testifies to this sensitivity. Thus, results could be significantly skewed one way or other by a strongly expressed prior view, or the opinion of someone seen as an opinion leader. This made the data collected open to the charge of not representing in an unbiased way the opinions of students in the class.

\section{Response Eliciting and Interpretation}

A different research issue can be found in Burns' (2003) original article description how at first students might be allowed to make a 'don't know' choice rather than a substantive response. But also how, with good humour in the class, this was subsequently erased from the whiteboard as 'fudging', since other students had made the effort to actually choose. Thus, the 'don't know' students were usually also encouraged to commit - just for the moment - to an 'in' or 'out' position. Obviously the main goal was pedagogical - getting active class participation, beginning to think sociologically. The suggestion in revisiting this exercise with research students, however, was to re-analyse this instructor guidance as 'interference' with the data collection process. This idea added another useful subject for reflection by research methods students evaluating the rights and wrongs of research methodologies generally. Developing skills to identify all kinds of possible influence on research results is a key area of social science learning.

Another, somewhat different point was occasionally made with research classes, depending on the run of discussion. The distribution of responses to the Likert question in the intensity extension of the exercise in Figure 3 shows a roughly normal distribution curve, although this varied from class to class. Exploration of measures of central tendency and variation, along with other sampling issues, was helped by being grounded in this familiar local data. This extended the exercise to compare the reconstructed class data with textbook diagrams of bell-curves, and standard deviation measures, and how these apply to other cohorts and larger populations.

\section{CONCLUSION}

Willingness to question whether existing teaching exercises work as well as they should, or whether exercises are still relevant, requires a degree of self-confidence and introspection. Revisiting the present teaching exercise achieved three things: firstly, it confirmed positive engagement with a new and younger student cohort in another country. Secondly, revisiting the exercise resulted in two innovations when adapting and revising it from its original application. These were developing a small quantitative aspect and incorporating a simple intensity measure, both yielding positive engagement with students and deepening the analytic value for class learning and better teaching. Thirdly, this subsequently led to a new application of the exercise to illuminate dilemmas in getting research methods classes and concepts to come alive for students. 
More generally, revisiting the "which-way-should-the-toilet-roll-hang?" exercise showed other insights that different instructors might consider using. First, themes of taboo or deviance are capable of considerable expansion. Mostly the sense of discussing a minor taboo topic has been used in this exercise as the engine that generated student interest and involvement, but it could also energise discussion in class sessions about things we can and cannot talk about, or not easily such as the norms surrounding such constraints. Second, it continues to be the case that biophysical/ water/ environmental concerns come up only infrequently even in this latest iteration of the exercise. However, the politics around industrial processes are significant: dioxin is used in bleaching toilet-paper white and is a highly toxic cancer-causing chemical, often discharged at unacceptable levels in water-ways, but little knowledge or interest was expressed by students (Gibbs, 1999). The social politics of water and sanitation (Purvis, 2015), or the uplifting story of making lives better for developing countries (Pholeros, 2013) provide further avenues for teaching and research.

Revisiting and checking the adequacy of existing class exercises after some time or in different institutional settings opens up new possibilities - re-invention, adaptation, replacement or extension. Literature that documents such revision, like the original publication of teaching and learning exercises, helps resource other teachers and further contributes to quality educational practice.

Edgar Burns has taught in the polytechnic and university tertiary sectors for more than twenty-five years. He takes an interdisciplinary approach starting from his core sociology teaching and research roles. His recent book Theorising Professions: A Sociological Introduction is published with Palgrave Macmillan.

(D) https://orcid.org/0000-0002-6645-3358

\section{REFERENCES}

Biggs, J., \& Tang, C. (2007). Teaching for quality learning at university. Maidenhead, UK: Open University Press.

Boyd, J., \& Boyd, S. (2005). Reflect and improve: Instructional development through a teaching journal. College Teaching, 53(3), | 0 - | |4. https://doi.org/I0.3200/CTCH.53.3.II0-I|4

Brouillette, J., \& Turner, R. (1992). Creating the sociological imagination and the first day of class: The social construction of deviance. Teaching Sociology, 20(4). 276-279. https://doi.org//0.2307//318968

Burns, E. A. (2003). Bathroom politics: Introducing students to sociological thinking from the bottom up. Teaching Sociology, 3 I (I), | 0 - I|8. https://doi.org/|0.2307/32||1429

Burns, E. A. (2016). Reflecting on first-year undergraduate journal insights from a class exercise. Waikato Journal of Education, $21(1), 55-64$.

Burns, E. A. (2017). Responding to student reaction to a simple spreadsheet exercise in a sociology undergraduate class. Spreadsheets in Education, 9(3), 1- 17.

Bryant, T. (1994). A bacterial identification teaching exercise revisited. Computer Applications in the Biosciences, 10(3), $329-334$.

Chappell, A. (2007). Using teaching observations and reflective practice to challenge conventions and conceptions of teaching in geography. Journal of Geography in Higher Education, 3/(2), 257-268. https://doi.org/I0.1080/0309826060 I06365I

Forman, J., \& Rymer, J. (1999). The genre system of the Harvard case method. Journal of Business \& Technical Communication, 13(4), 373-400. https://doi.org//0.1177//0506519990130040।

George, A., \& Bennett, A. (2005). Case studies and theory development in the social sciences. Cambridge, MA: MIT Press.

Gibbs, L. M. (1999). Dying from dioxin. Cambridge, MA: South End Press.

Haney, T. J. (2009). Doing what sociologists do: A student-engineered exercise for understanding workplace inequality. Journal of the Scholarship of Teaching \& Learning, 9(3), 56-69.

Kaufman, P., \& Schoepflin, T. (2009). Last but not least: The pedagogical insights of "intellectual craftsmanship." Teaching Sociology, 37(I), 20-30. https://doi.org/10.1 I77/0092055X0903700103 
Law, A. (2007). Sociology and the pedagogy of common sense: Dialogues with "non-traditional" sociology students in a new Scottish university. Learning \& Teaching in the Social Sciences, 3(3), I5I-169. https://doi.org/|0.1386/Itss.3.3.15।_I

Metzger, M. (2003). Revising teaching. English Journal, 93(2), 53-57.

Montemurro, B. (2008). Toward a sociology of reality television. Sociology Compass, 2(I), 84-I06. https://doi.org/l0.1III/j. I75I9020.2007.00064.x

Nefes, T. (2013). Teaching sociology seminars through The Simpsons: Homer under C. Wright Mill's eye. Journal of Sociology, 50(2), II5-131. https://doi.org//0.1177//4407833/2440755

Nye, A. Hughes-Warrington, M. Roe, J. Russell, P. Deacon, D., \& Kiem, P. (201I). Exploring historical thinking and agency with undergraduate history students. Studies in Higher Education, 36(7), 763-780. https://doi.org/I0.1080/0307507I003759045

Paul, J. (2006). "Flushing" out sociology: Using the urinal game and other bathroom customs to teach the sociological perspective. Electronic Journal of Sociology, I-14. https://www.shortcutstv.com/blog/wp-content/uploads/2016/09/johnpaul_the_urinal_ game.pdf

Pholeros, P. (2013). How to reduce poverty? Fix homes. TEDxSydney. Retrieved from https://www.ted.com/talks/paul_pholeros_ how_to_reduce_poverty_fix_homes

Purvis, K. (20I5, I July). Access to clean water and sanitation around the world - mapped. Guardian. Retrieved from https://www. theguardian.com/global-development-professionals-network/20I5/jul/0l/global-access-clean-water-sanitation-mapped

Rosenquist, C. (2012). Visual form, ethics, and a typology of purpose: Teaching effective information design. Business and Professional Communication Quarterly, 75(I), 45-66. https://doi.org//0.1177/10805699||428670

Shulman, L. (1998). Course anatomy: The dissection and analysis of knowledge through teaching. In P. Hutchings (Ed.), The course portfolio: How faculty can examine their teaching to advance practice and improve student learning (pp. 5-12). Washington, DC: American Association for Higher Education.

Sullivan, D. (20II). Egg-drop exercise revisited: An in-class entrepreneurship exercise. Journal of Entrepreneurship Education, 14(4), 49-73.

Trigwell, K., \& Shale, S. (2004). Student learning and the scholarship of university teaching. Studies in Higher Education, 29(4), 523536. https://doi.org/I0.1080/0307507042000236407

Turcsanyi-Szabo, M., Bedo, A., \& Pluhar, Z. (2006). Case study of a team challenge game: e-PBL revisited. Education \& Information Technologies, II(3-4), 34I-355. https://doi.org/I0.1007/sI0639-006-9015-3

Warner, A. (2005). An egg-centric approach to teaching strategic types: Adapting a classic exercise. Journal of Management Education, 29(4), 583-592. https://doi.org//0.1177//052562904272435 